\title{
Feasibility of Development of an Immunization Management Tool for Mobile Phones by UCD Approach
}

\author{
A Chowdhury \\ Dept. of Design, \\ Indian Institute of \\ Technology \\ Guwahati, \\ Guwahati-781039, \\ Assam, India.
}

\author{
H Gebretsadik \\ Dept. of Design, \\ Indian Institute of \\ Technology \\ Guwahati, \\ Guwahati-781039, \\ Assam, India.
}

\author{
S Kumar \\ Dept. of Design, \\ Indian Institute of \\ Technology \\ Guwahati, \\ Guwahati-781039, \\ Assam, India.
}

\author{
R M Punekar \\ Dept. of Design, \\ Indian Institute of \\ Technology \\ Guwahati, \\ Guwahati-781039, \\ Assam, India
}

\begin{abstract}
Mobile phones are the most used accessories of people throughout the world and its uses are increasing day by day in India [20]. Due to advancement in the field of 'Human Computer Interaction (HCI)' in the last few decades, attention has been drawn to usability studies of mobile devices or mobile phone applications including user need identification, user need analysis, usability testing etc. In the area of health, Immunization as such has prime importance in human life especially to protect newborns and teenagers from life threatening diseases. In India, present immunization program involves pen-paper based routine immunization (RI) card which has several drawbacks in its use; such as, spoiling of RI card, RI card being lost etc. Due to these reasons vaccines have not been disseminated properly among children. However, technologycan assist in such man-made insensibilities, mistakes and inabilities. So, in this context, before any direct technological intervention in this domain of application, it is necessary to evaluate the feasibility of technological intervention to solve this problem by identifying user need. In this paper, an attempt has been made to evaluate user need identification for design and development of an electronic immunization management tool (IMT) for mobile phones under taking user centered design approach. The current paper describes user's responses and needs towards design and development of this tool that aims at inspiring people to give vaccines to their child properlyandboosting the existing immunization management system in near future.
\end{abstract}

\section{General Terms}

Human computer interphase / interaction, User experience, Usability engineering, Immunization management tool (IMT).

\section{Keywords}

HCI, User Centered Design (UCD), Immunization, Mobile Tool/ Application, User survey, User research.

\section{INTRODUCTION}

The use of mobile phones throughout the world has a reach of about 6 billion (around $87 \%$ of the total world population). In case of mobile phone usage, China, India and United States are holding the top three positions [16]. India is second leading country in mobile/wireless use with 960.90 Million users (Detail distribution of wireless subscribers are furnished in Table 1.). In addition to that, recent telecom plan of Govt. of India, aims to cover maximum rural population with mobile phone connectivity by 2020 [19].
Table 1. Distribution of mobile/ wireless users among urban and rural area [20]

\begin{tabular}{|c|c|c|c|}
\hline $\begin{array}{c}\text { Connection } \\
\text { type }\end{array}$ & $\begin{array}{c}\text { Total } \\
\text { Subscribers } \\
\text { (Millions) }\end{array}$ & $\begin{array}{c}\text { Urban } \\
\text { Subscribers } \\
\text { (Millions) }\end{array}$ & $\begin{array}{c}\text { Rural } \\
\text { Subscribers } \\
\text { (Millions) }\end{array}$ \\
\hline $\begin{array}{c}\text { Wireless/ } \\
\text { mobile }\end{array}$ & 960.90 & 621.21 & 339.69 \\
\hline
\end{tabular}

In India, the infant mortality rate, neonatal mortality rate and under 5 mortality rate are 50, 34 and 64 per 1000 live births respectively; the main cause which can be attributed topoor child health scenario. Around $40 \%$ of infant deaths are caused from respiratory infections, diarrheal disease and other infectious and parasitic diseases. All these information are supportive to importance of vaccinations [4]. On the other hand, major causes of mother's deaths in India are hemorrhage (both ante and post-partum), toxemia (hypertension duringpregnancy), anemia, obstructed labour, puerperal sepsis (infections after delivery) and unsafe abortion [4]. So, regular health checkup is very essential for both mother and child. In India, currently mother and child health program are running simultaneously and these are practiced/maintained through a common routine immunization (RI) health card/RI card. Present RIcard records not only includeroutine immunization schedule, but it also covers frequent health checkup schedules for child and mother (to cure and assist problems before and after pregnancy). Moreover, instructions for PHC workers for emergency situations, and responsibilities of parents after child's birth are also furnished in this card. So, thisRI card records provides basic data set for the public healthcare (PHC) workers/ Frontline Healthcare Worker (FHW) or service provider as well as the recipients (child along with their parents).Three grades of FHWs have been observed viz. Assistant NurseMidwife (ANM), Accredited Social Health Activist (ASHA), and Anganwadi Worker (AWW), each FHWs are handling this RI card along with recipient.

A group of authors [1] argued on the present immunization system that there is chance of loss of RI card and loss of RI card data due to spoilage of pen-paper based RI card.In addition to that more time is taken to manage huge amount of sample registration data through pen-paper based system. So, in this context proper handling of these data is very important and as such technological intervention may be necessaryas these data are vital for both mother and child health. Another drawback of pen-paper based RI card is that it is less interactive than the other similar, available, interactive mobile 
tools like pregnancy management tool in iPhone. So, in these contexts technological intervention may be necessary.

Even though the present immunization program in India has shown a considerable growth and development as far as improvement is concerned yet it can't be said that Indian vaccination program is up to the highest mark. The Indian Health Minister in a meeting of the WHO at New Delhi recently said that to track mothers 'to ensure their babies receive the full repertoire of immunizations' could be done through their mobile phones [2]. So, mobile tool/application development may be fruitful for promoting present immunization management system as well as removing drawbacks of the present immunization system.

Contextually, recent trend of research in the field of HCI is 'User Centered Design (UCD)' approach [6, 7, 10, 12, 14] and this has been taken for making mobile tool/application more usable[6, 8, 9, 13, 22, 24].User centered design approach involves techniques including - ethnography, participatory design, focus group research, user surveys, walk-throughs, open and closed card sorting, paper prototyping, heuristics evaluation, usability testing and follow-up-studies $[3,5,11$, $14,21,23]$. Sometimes researchers/usability engineers use all these methods collectively or uniquely, depending on the context of the design and development.Usability testing of mobile tool, mobile applications are now very popular in UCD methods [13]. In addition, there are some primary methodspresented in Table 2, many researchers have been adapted for identifying the users' needs at the initial stage of product development. However, user survey although can be used at any time in the product lifecycle, are most often used in the early stages to understand better the potential users [21]. Hence, user survey is one of the important techniques to identify the user's need $[15,17]$ and may be used for design and development of any mobile application/tool.

Table 2.Primary measures for users' needs identification

\begin{tabular}{|l|c|}
\hline \multirow{2}{*}{ Measures } & Ethnography \\
\cline { 2 - 2 } & Focus Groups research \\
\cline { 2 - 2 } & Structured Interviews \\
\cline { 2 - 2 } & User Surveys \\
\hline
\end{tabular}

Keeping all these information in mind, certain questions come to the fore: 1) Will mobile phone based immunization management tool be accepted/appreciated by the recipients of RI health card and FHWs? 2) How much can recipients/parents afford to purchase a mobile phone with this immunization management tool? 3) How much are recipients/FHWs habituated with use of mobile phone? 4) Will FHWs/PHC workers use/handle this tool in near future? 5) How much are recipients/parents familiar with present mobile tool use? 6) How much are recipients/parents aware about immunization programs and procedures? 7) Are mothers'/children taking vaccines properly? 8) Is there any mistake in remembering the date of vaccinations? 9) In which language do recipients (FHWs/PHC workers) prefer to use this tool? etc. To answers all these questions and to understand the feasibility of design and development of immunization management tool/application for mobile phones a user survey has been carried out. This helps to find out users' needs identification before design. Detail methods, results, discussions and conclusions are described towards design and development of IMT in the subsequent sections.

\section{METHODS}

A pre-design user survey was carried out with 33 respondents to understand the feasibility of development of an immunization management tool. For that purpose, the authorshad built two questionnaires (one for PHC workers and another for Parents) (Questionnaires includegeneral demographic information of the respondents, immunization management related items and IMT designfeasibility related items). These two questionnaires constructedwith some openendedquestions; questions having answers in yes/no responses and some questions constructed usingLikert scale. In the Likert scale that was employed for the purpose,response ' 1 'stood for strongly disagrees and ' 5 'stood for strongly agree [21]. These questionnaires were standardized following pretest method as described in literature [18]. Among these questionnaires, one questionnaire was usedfor collecting feedback from PHC workers (Medical Officers, ANM (Auxiliary Nurse Midwife), AWW (Anganwadi Workers) and ASHA staff and another questionnaire was used for parentswho had at least one child of age group 1-16 years i.e. age group for vaccination of children. All the respondents were from north-east India (Assam and West Bengal) participatedin the present study voluntarily without receiving any monetary payment.

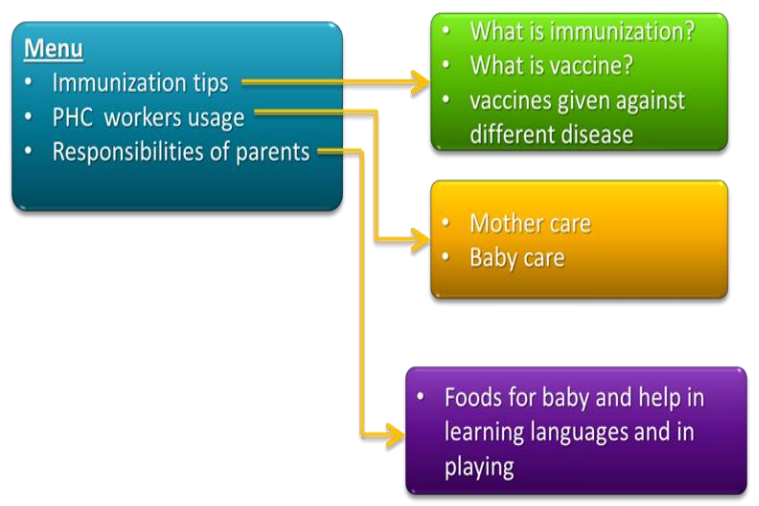

Fig 1: Chart showingsample navigation points withmain key components

With standardized questionnaires, feedbacks were taken after describing the objectives of this design and development (Table 3.). Authors also presented a sample navigation chart proposing for design and development of this tool to the respondents (Fig 1) before taking responses. Data were

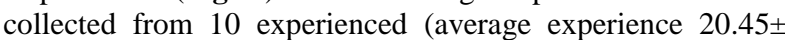
2.67 years) PHC workers and 23 parents with Indian citizenship. After collecting all data through questionnaires, these were analyzed by using Microsoft Excel. Descriptive statistics (Frequency, Mean \pm SD and Percentage of data) were used for final conclusion. 
Table 3. This table furnishing design goals describedto the respondents before taking responses through questionnaire.

\begin{tabular}{|c|c|}
\hline \multirow{4}{*}{$\begin{array}{c}\text { Design goals of } \\
\text { immunization } \\
\text { management tool design } \\
\text { and development for } \\
\text { mobile phones }\end{array}$} & $\begin{array}{l}\text { Design and development of a } \\
\text { mobile tool including } \\
\text { immunization tips and } \\
\text { electronic routine } \\
\text { immunization (RI) card } \\
\text { because some problems were } \\
\text { found in paper based RI card } \\
\text { as evident from literature. }\end{array}$ \\
\hline & $\begin{array}{l}\text { This immunization card } \\
\text { enables alarming facility } \\
\text { whichin turn helps people to } \\
\text { remember the exact date of } \\
\text { immunization. }\end{array}$ \\
\hline & $\begin{array}{l}\text { PHC data management } \\
\text { facility which are generally } \\
\text { filled by PHC workers. }\end{array}$ \\
\hline & $\begin{array}{l}\text { Instructions for parents: } \\
\text { Responsibilities of parents to } \\
\text { their growing child. }\end{array}$ \\
\hline
\end{tabular}

\section{RESULTS}

\subsection{Age and Sex of target users}

Among parents who were participated in the study, the average age of male participant was approximately $38.33 \pm 4.76$ and that of female participant was 37.88 \pm 9.64 . Total $65.22 \%$ male and $34.78 \%$ of female parents wereparticipated in this study (Fig 2).Among the PHC workers $90 \%$ were female and $10 \%$ were male. Average ages of PHC workers were $39.11 \pm 8.88$ and 42 years for female and male PHC workers respectively (Fig 3).

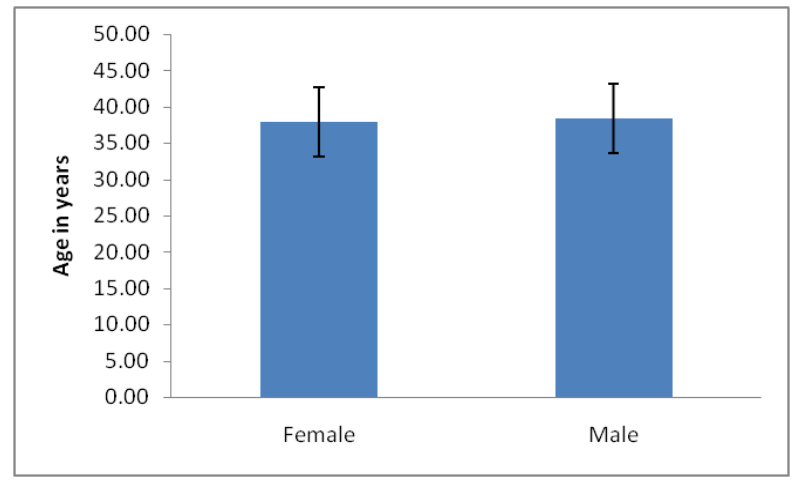

Fig 2: Sex wise age distribution of parents

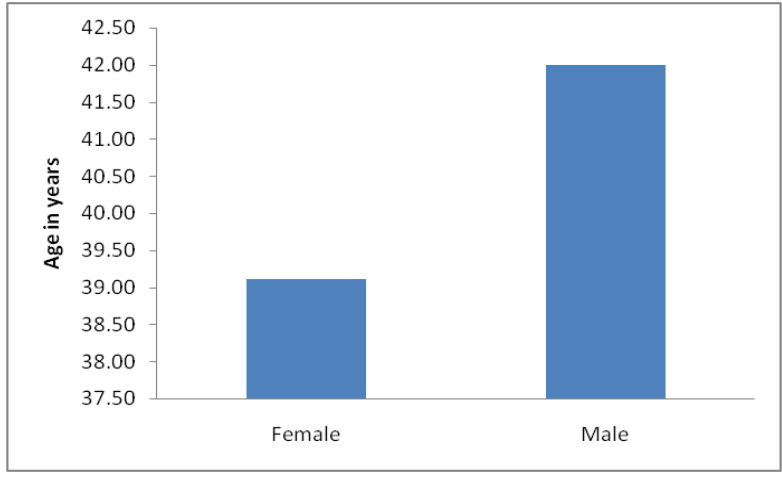

Fig 3: Sex wise age distribution of $\mathrm{PHC}$ workers

\subsection{Age and sex distribution of the children of the users (Parents)}

In the present study, the number of children who took vaccineswas9 and 18 for male andfemalerespectively. Their sex wise average agewere $6.89 \pm 1.62$ in case of male and $7.83 \pm 1.03$ in case of female

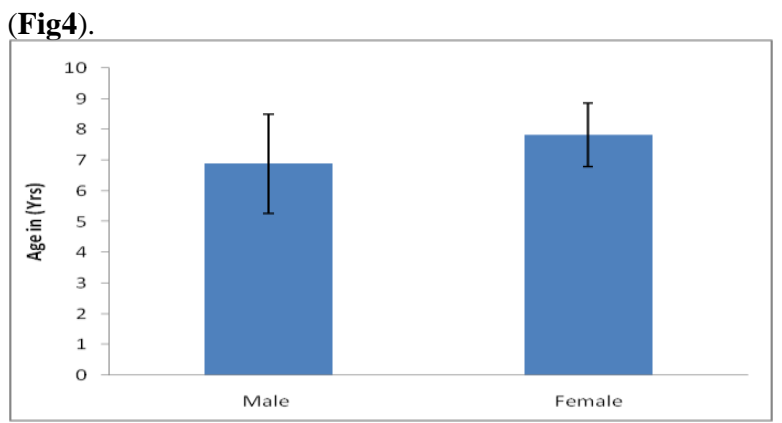

Fig 4: Sex wise age distribution of children

\subsection{Family income vs. affordability of parents}

Presently parent groups on an average possess 3 mobile phones per family and their average family income is Rs.36565.22. Parents who have more family income wanted to buy a new mobile phone with new feature in higher range and vice-versa, which is presented in Fig 5. On examining \% wise distribution of affordability to buy a new mobile phone with the proposed features for this study indicates that $34.78 \%$ respondentswere willing to buy a new mobile phone in the range of Rs.- 5,000 to 10,000 and most respondents (73.91\%) can afford above Rs. - 2000 to buy a mobile phone (Fig 6).

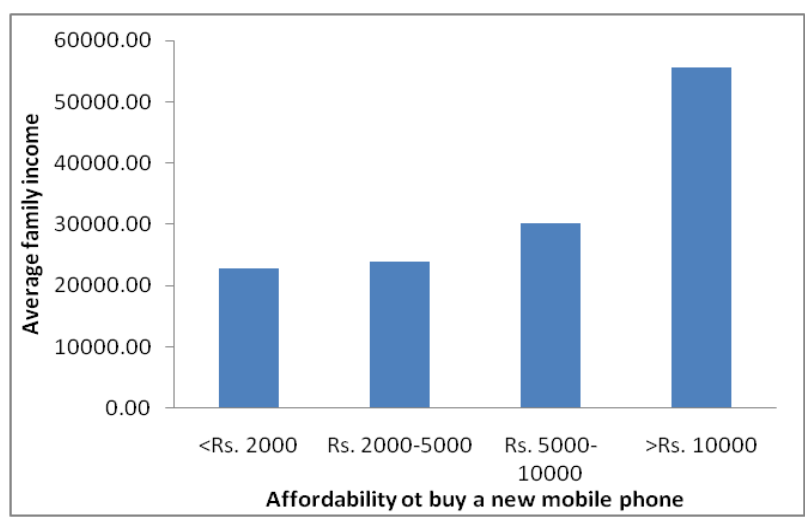

Fig 5: Family income versus affordability 


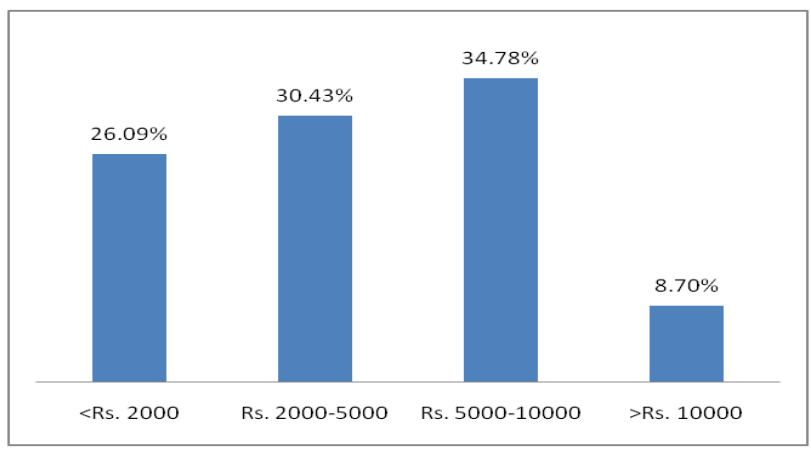

Fig 6: Exploration of range of affordability to purchase a new mobile phone with new feature

\subsection{Status of maintenance of RI schedule}

This study shows that $86.96 \%$ parents are maintaining routine immunization schedule properly as instructed by doctor/ other PHC workers (Fig7). Around $13.04 \%$ parents are unable to maintain routine immunization card properly. Among them some parents wereforgotten the exact date $(75 \%)$ of vaccination while the rest $(25 \%)$ were aware of the date but were not able to give vaccines to their child due to some personal reasons (data not shown).

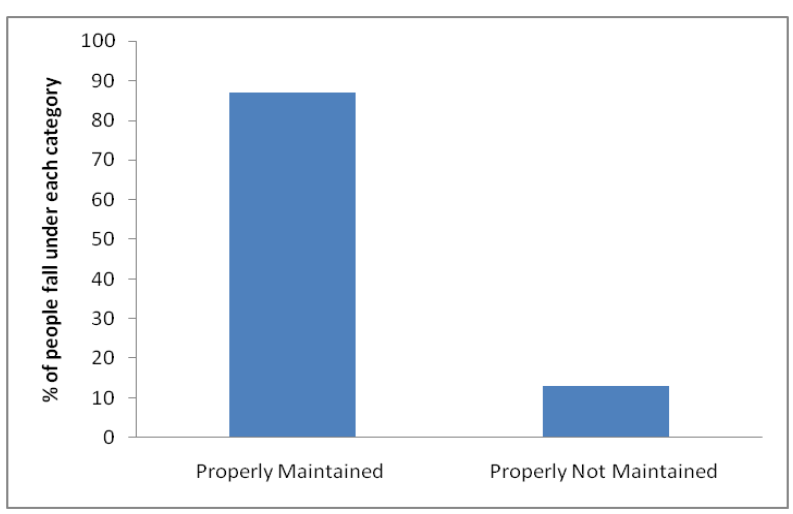

Fig 7: Percentage distribution of maintenance of routine immunization schedule

\subsection{Knowledge about vaccination among parents}

From this study it is seen that $56.52 \%$ of parents knowswhy vaccines are given to their child while $43.48 \%$ are unaware as to why vaccines are given (Fig 8). From the analysis of educational literacy level of those who don't know why vaccines are given, it was found that $30 \%$ people had completed primary education, $10 \%$ people had completed higher secondary education, $40 \%$ of the total people had completed higher secondary education and $20 \%$ of the people had completed bachelor's degree (Fig 9).Among the category of parents who were unaware as to why vaccines were given, around $90 \%$ of them wanted to know why vaccines were given, in future.

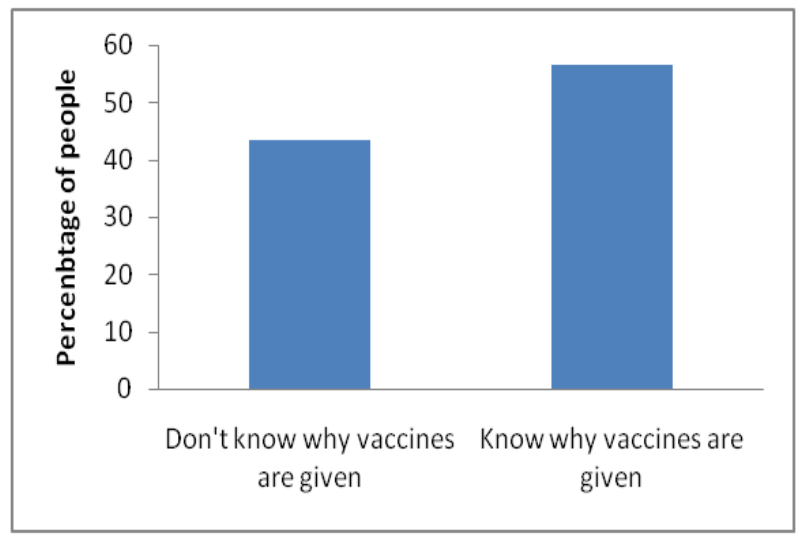

Fig 8: Knowledge about vaccination among parents

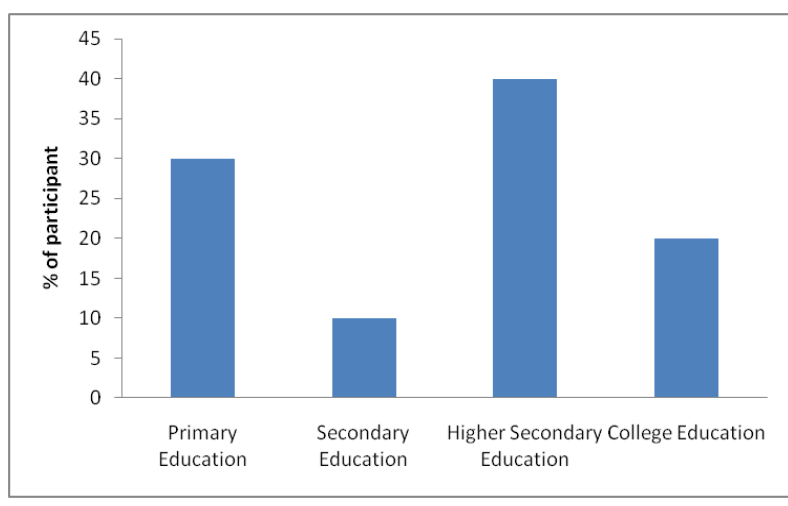

Fig 9: Education level of the participants who don't know why vaccines are given

\subsection{Usability parameters of mobile phone use}

\subsubsection{Parent users}

Parents who had agreed to use this proposed tool weremore habituated with mobile phones than those who haddisagreed to use IMT. The mean value shows that users of both groups prefer to use IMT intheir regional languages rather than English language (Table 4.).

\subsubsection{PHC workers}

Those PHC workers who wanted to use electronic RI card in their mobile, were well habituated with mobile phones but their internet searching ability through mobile phones were less than that of the average level. In addition to that, they responded that they had never used this kind of system previously. However, they strongly agreed that they would use the proposed electronic immunization management tool in their mobile in future (Table 5.). 
Table 4.Data of the parent user derived from questionnaire based on Likert Scale

\begin{tabular}{|c|c|c|}
\hline \multirow[b]{2}{*}{$\begin{array}{l}\text { Statements/ } \\
\text { Items }\end{array}$} & \multicolumn{2}{|c|}{ Likert Score $($ Mean \pm SD) } \\
\hline & $\begin{array}{l}\text { Willing to use } \\
\text { electronic } \\
\text { immunization } \\
\text { management } \\
\text { toolin mobile } \\
\text { phone } \\
(n=20)\end{array}$ & $\begin{array}{l}\text { Not willing to } \\
\text { use electronic } \\
\text { immunization } \\
\text { management tool } \\
\text { in mobile phone } \\
(\mathrm{n}=3)\end{array}$ \\
\hline $\begin{array}{l}\text { Habituated to use } \\
\text { tools in mobile } \\
\text { phone }\end{array}$ & $\begin{array}{c}4.20 \\
\pm 0.77\end{array}$ & $\begin{array}{c}2.33 \\
\pm 1.53\end{array}$ \\
\hline $\begin{array}{l}\text { I am able to use } \\
\text { electronic routine } \\
\text { immunization tool } \\
\text { in English }\end{array}$ & $\begin{array}{c}3.55 \\
\pm 1.61\end{array}$ & $\begin{array}{c}2.33 \\
\pm 2.31\end{array}$ \\
\hline $\begin{array}{l}\text { I am able to use } \\
\text { electronic routine } \\
\text { immunization tool } \\
\text { in regional } \\
\text { languages in } \\
\text { India. }\end{array}$ & $\begin{array}{c}4.15 \\
\pm 1.46\end{array}$ & $\begin{array}{c}3.33 \\
\pm 2.08\end{array}$ \\
\hline
\end{tabular}

Table 5.Data of the PHC workers derived from questionnaire based on Likert Scale

\begin{tabular}{|c|c|c|}
\hline \multirow[b]{2}{*}{$\begin{array}{l}\text { Statements/ } \\
\text { Items }\end{array}$} & \multicolumn{2}{|c|}{ Likert Score (Mean \pm SD) } \\
\hline & $\begin{array}{l}\text { Willing to use } \\
\text { electronic } \\
\text { immunization } \\
\text { management } \\
\text { toolin mobile } \\
\text { phone } \\
(n=9)\end{array}$ & $\begin{array}{l}\text { Not willing to } \\
\text { use electronic } \\
\text { immunization } \\
\text { management } \\
\text { tool in mobile } \\
\text { phone } \\
(n=1)\end{array}$ \\
\hline $\begin{array}{l}\text { Habituated to use tools } \\
\text { in mobile phone }\end{array}$ & $\begin{array}{c}4.22 \\
\pm 0.83\end{array}$ & Not applicable \\
\hline $\begin{array}{l}\text { Habituated with } \\
\text { internet searching by } \\
\text { using mobile phone }\end{array}$ & $\begin{array}{c}2.44 \\
\pm 1.33\end{array}$ & Not applicable \\
\hline $\begin{array}{l}\text { I have already used this } \\
\text { kind of system } \\
\text { previously }\end{array}$ & $\begin{array}{c}1.00 \\
\pm 0.00\end{array}$ & Not applicable \\
\hline $\begin{array}{l}\text { I am willing to use this } \\
\text { kind of system in future }\end{array}$ & $\begin{array}{c}4.78 \\
\pm 0.44\end{array}$ & Not applicable \\
\hline
\end{tabular}

\subsection{Willing to use the proposed tool}

From the questionnaire study after giving the proposals and discussing the study goal it is evident that around $86.96 \%$ of parents who participated are willing to use the proposed system and rest of them (13.04\%) are unwilling to use it.

Similarly, around $90.00 \%$ of the health workers are willing to use the electronic routine immunization schedule and rests are unwilling to use. In addition it may be noted from response of PHC workers to some open ended questions that suggestedin account of further improvement of the proposed tool and they are also willingness to use internet based electronic data management system if training is provided to them.

\section{DISCUSSIONS}

Though vaccines are given at any age of human life for emergency purpose, in this study parents wereparticipated considerably who had children in between the age group of 116 years i.e. the age group for taking vaccines by the children to build immunity. Another interesting finding from this study is that vaccines were given to a good number of girls as compared to boys (Fig 4).

In the present study, it is found that although each family is using 3 mobile phones on an average they still want to buy better mobile phone with new features. Average family income of the participated parent group is that of the Indian middle class family (around Rs.- 36565.22). Additionally, present study shows thatto buy a new mobile phone with proposed featuresof immunization management tool, maximum people $(73.91 \%)$ can afford to buy the product in the range of Rs.2000 to 5,000; around $43.48 \%$ people can afford in the range of Rs.5000 to 10,000 (Fig 6). This scenario supports the feasibility of design and development of proposed immunization management tool for mobile phones since mobile phones ofrange are available in the market with this kind of applications.

The authors while looking at the immunization schedule maintenance, found that parents who maintained routine immunization schedule properly as per instructions of PHC workers/FHWs consisted of $86.96 \%$, while who did not maintain consisted of $13.04 \%$. Most of the people $(75 \%)$ forgot the exact date for a particular vaccination to be given. This data supports that to reach the goal of $100 \%$ vaccination to the child (as aimed by Indian government),there is enough scope to design and develop immunization management tool with alarm/ reminder feature. As such, it is possible to boost present immunization program.

Parents $(43.48 \%)$ don't know why vaccines are given though all of them have completed their primary education and most have also completed their higher secondary education. Interestingly, most of them (90\%) like to beaware aboutimmunization and vaccination.So, in a way there is a scope forincorporationof Immunization Tips feature' in the proposed tool.In fact, it may imply that awareness of the parents about immunization will grow.

Maximum users $(86.96 \%$ parents and $90.00 \%$ PHC workers)were willing to use the proposed tool in near future, so, there is high scope for development of the Immunization Management Tool (IMT). Remarkably, it is also found that FHWs/PHC workers are willing to use Internet based electronic data management system if training is provided to them.

After evaluating the familiarity with mobile phone among both parents $(86.96 \%)$ and PHC workers $(90.00 \%)$ who were willing to use the proposed tool, it was found that they are well habituated with mobile tool use (Table 3. And Table 4.). From the results (Table 3.) parents were likely to use the proposed tool more in regional languages rather than the English language. In this context, it must be noted that the good electronic font types of all regional languages of India is not available in graphic design application software like 'AdobeMaster Collections', 'Corel DRAW' etc. Whatevermay be the case, it is possible to develop this proposed tool at least in Hindi (i.e. national language of India) and in English.

Although PHC workers are not habituated with electronic data management system by using Internet and have never used 
similar technology previously, they are willing to use mobile tool similar to proposed one on being given training. This implies that there is possibility to incorporate this feature in this mobile tool. So, most of the data from user survey are in favor of design and development of immunization management tool (IMT) for mobile-phones.

\section{SUMMARY AND CONCLUSIONS}

To summarize, the following points are essential - 1) Immunization is mandatory for all mothers and children to prevent mother's mortality and premature childdeath; 2) Immunization program is maintained through RI health card; 3) Present pen-paper based RI card is problematic to handle by recipients as well as frontline health workers; 4) To address this problem technological intervention is necessary; 5) Mobile application/tool development for immunization management may be an option considering the large number of mobile phone users/ wireless subscribers in India; 6) UCD approach,the current and advanced practice, will be appropriate to develop this kind of mobile application $[8,9$, $13]$; 7) the Authors have developed a featured proposal for this kind of immunization management tool ; 8) Based on UCD approach an user survey wasconducted for understanding the user's need and feasibility of development of this tool [17]; 9) It is revealed from the results and discussions that most of the data supports development of this immunization management tool.

It can be concluded that there is a need of proposed tool among the target user groups viz. parents and FHWs/PHC workers. In this context an Android based immunization management tool may be developed with more detail usability study using different usability techniques such as paper prototyping and card sorting for more detail menu preparation and navigation design; usability testing: perceived ease of use etc. after preparing detail prototype of this mobile tool.

One of the limitations for development of the proposed tool is unavailability of good font types of regional languages in India. Designers can take this as an opportunity to develop regional fonts that are not suitablecurrently. As maintenance of routine immunization is mandatory for all people of India and also for rural people of India with relatively lowerseconomic status, finally, it is urged that the proposed tool can be incorporated in the low cost mobile phones.

\section{REFERENCES}

[1] Abhisek, R., Raman, S., Mukhtar, M., Ohri, E., SahaMitra, S. and Sood, A. D., 2011. Mobile Health Card: How to Use Mobile Phones to Increase Rural Immunization Rates. http://ebookbrowse.com/mobilehealth-card-how-to-use-mobile-phones-to-increase-ruralimmunization-rates-pdf-d214376725

[2] Anand, G., 2011. India Turns to Mobile Phones in Bid to Improve Vaccination Rate. The Wall Street Journal, (August 2011) http://blogs.wsj.com/indiarealtime/2011/08/04/indiaturns-to-mobile-phones-in-bid-to-improve-vaccinationrate/

[3] Angeli, A. D., Sutcliffe, A. and Hartmann, J., 2006.Interaction, usability and aesthetics: what influences users' preferences? In Proceeding DIS '06 Proceeding of the 6th conference on Designing Interactive systems

[4] Annual Report 2011-2012, Department of Health and Family Welfare, Ministry of Health and Family Welfare, Government of India. www.mohfw.nic.in
[5] Bai, Z. and Blackwell, A. F., 2012. Analytic review of usability evaluation in ISMAR. Interact. Comput., 24 (November 2012), 450-460.

[6] Burigat, S. and Chittaro, L., 2011. Visualizing references to off-screen content on mobile devices: A comparison of Arrows, Wedge, and Overview + Detail. Interact. Comput., 23 (February 2011), 156-166.

[7] Chen, C.A., 2012. Discussion on increasing college teachers' willingness to adopt web-based learning in teaching. Bus. Manag. Res., (July 2012), 1-8.

[8] Fiorella, D., Sanna, A. and Lamberti F., 2010. Multitouch user interface evaluation for $3 \mathrm{D}$ object manipulation on mobile devices. J Multimodal User Interfaces, 4 (March 2010), 3-10.

[9] Gargar, M. and Whorter, R.M., 2012. South Sudan deploys new mobile phone-based stock management tool. OP.TI. MIZE, 14 (October 2012), 1-12.

[10] Gulliksen, J., Ransson, B. G., Boivie, I., Blomkvist, S., Persson, J. And Cajander, A. S., 2003. Key principles for user-centred systems design. Behav. Inform. Technol., 22 (November-December 2003), 397-409.

[11] Hendersona, R. and Divett, M. J., 2003. Perceived usefulness, ease of use and electronic supermarket use. Int. J. Human-Computer Studies, 59 (September 2003) 383-395.

[12] Hornbaek, K., 2006. Current practice in measuring usability: Challenges to usability studies and research. Int. J. Human-Computer Studies, 64 (February 2006), 79-102.

[13] Kaikkonen, A., Kallio, T., Kekäläinen, A, Kankainen, A., Cankar, M., 2005. Usability Testing of Mobile Applications: A Comparison between Laboratory and Field Testing. Journal of Usability Studies, 1 (November 2005), 4-16.

[14] Law, E. L-C., and van Schaik, P., 2010. Modelling user experience - An agenda for research and practice. Interact. Comput., 22 (September 2010), 313-322.

[15] Lindgaard, G., Dillon, R. and Trbovich, P.(2006). User Needs Analysis and Requirements engineering: Theory and Practice. Interact. Comput., 18 (January 2006), 47 70.

[16] List of countries by number of mobile phones in use.http://en.wikipedia.org/wiki/List_of_countries_by_n umber_of_mobile_phones_in_use

[17] Mao, J-Y.,Vredenburg, K., Smith, P. W. and Carey, T., 2005. The State of User-centered Design Practice. Commun. ACM, 48 (March 2005), 105-109.

[18] Malhotra, N.K. and Dash, S., 2011. Marketing Research. Dorling Kindersley (India) Pvt. Ltd.

[19] National Telecom Policy - 2012 (NTP - 2012). http://www.dot.gov.in/ntp/NTP-06.06.2012-final.pdf

[20] Pal, R., 2012. Press Release No. 143/2012. Technical Report. Telecom Regulatory Authority of India at India.

[21] Rubin, J. and Chisnell, D., 2008. Handbook of Usability Testing. Wiley Publishing, Inc.

[22] Usability Test Report for Mobile Applications, 2012 http://www.technical-direct.com/2012-05/usability-testreport-for-mobile..

[23] Whitea, R., Fernandesa, G., Lundahlb, S. and Pinnamaneni, A., 2006. User Needs Analysis and requirements engineering: Theory and practice. Interact. Comput., 18 (January 2006), 47-70.

[24] Yim, S., Lee, S. and Choi, S., 2011. Evaluation of motion-based interaction for mobile devices: A case study on image browsing. Interact. Comput., 64, (February 2006), 79-102. 